\title{
Presidential address 2015
}

Presidential address of the $20^{\text {th }}$ Annual Scientific Sessions of the Sri Lanka College of Venereologist (College for sexual health and HIV medicine in Sri Lanka) by Dr Ajith Karawita.

Chief Guest Prof Ranjith Wijayawardena, Vice-chancellor, Rajarata University of Sri Lanka,

Guest of honour Prof Lavinia Crooks, Distinguished invitees from abroad, Past presidents, Fellows of the college Members of the council, Members of the college, My teachers, friends, ladies and gentlemen;

The theme of the $20^{\text {th }}$ Annual Scientific Sessions and today's my keynote address is "Sexual health in the Era of HIV"

First of all, I would like to take you through the sub topics of my presentation on the theme;

- HIV epidemic in Sri Lanka

- HIV treatment cascade in Sri Lanka

- Challenges in closing the gaps in HIV treatment cascade

- HIV in the broader concept of Sexual Health

\section{HIV epidemic overview in Sri Lanka}

As you all know Sri Lanka is an Island country, with a population of about 21 million living in a land area of approximately 65,000 square kilometres. It is a multiethnic, multilingual and multicultural country.

In the history timeline of HIV in Sri Lanka, first case of HIV reported in 1987, since then there has been a gradual increase in number of cases reported to the National STD/AIDS Control Programme. As of end 2014, 2074 cumulative number of cases reported from the first case in 1987 and in the last three years average of 203 cases reported per each year (Fig 1)

\section{Figure 1: History of HIV in Sri Lanka}

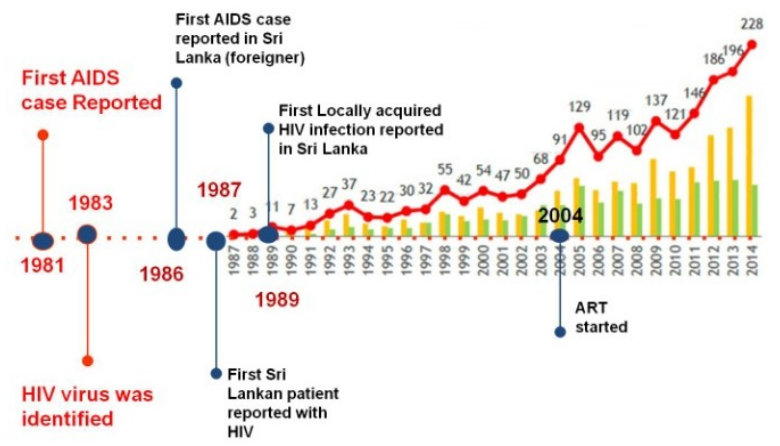

Currently it is estimated that about 3600 people are living with HIV and every year $<500$ new infections are being added and about $<200$ number of estimated AIDS death occur. No province or district is exempted. Over half of them (56\%) are reported from the Western Province of Sri Lanka.

However, analysis of new cases reported in 2014 shows that most of them are reported in the districts of Colombo, Gampaha, Kalutara, Kandy, Puttalam and Polonnaruwa. Rate of new cases per 100,000 population shows that Puttalam has over 10 cases per 100,000 population while Colombo, Gampaha, Kalutara and Polonnaruwa reported about 510 cases per 100,000 population (Fig 2)

Figure 2: Number of new cases vs. rate of new cases per 100,000 populations in 2014

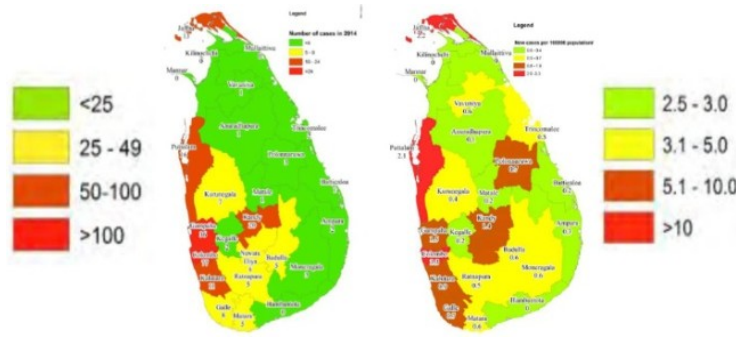

In simple and easy statistics, 07 new HIV infections occur in each week and only 04 cases reported to the National STD/AIDS Control Programme in the country. This shows a clear gap in case detections. 
Analysis of main mode of transmission in each year from 2003 to 2014 (Fig 3) shows that the main mode of HIV transmission is heterosexual and the heterosexual epidemic is more prominent. However, there is a gradual increase in the proportion of homosexual transmissions over the last years while negligible number of cases reported from possible infections through injecting drug use. Perinatal transmission ranges from $2-8 \%$ during the period. No cases have been reported due to blood and blood product transfusions. Increasing proportion of homosexual transmission may be due to increase testing coverage that is being conducted through peer lead interventions under the GFATM grants. It is important to note that there are substantial proportions where mode of transmission is unknown or uncertain. These groups need to be researched as samples to estimate about the mode of transmission.

Figure 3: Trend of probable mode of transmission 2003-2014

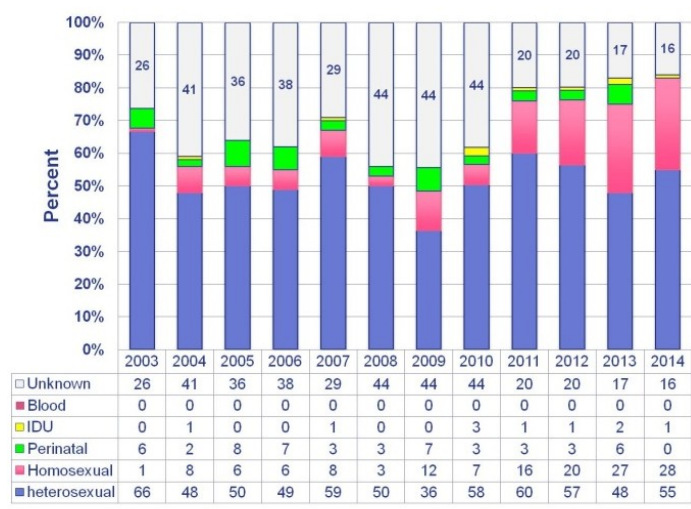

Distribution of HIV cases by the age (Fig: 4) shows that majority; about $75 \%$ of cases are reported in the age group of 25-49 years. It is important to note that about $7 \%$ of cases are reported in the age group of 15-24 years which is used as the proxy value for new HIV infections. That means out of all the cases reported in each year; about $7 \%$ are possibly due to new infections.
Figure 4: Reported HIV cases by age group 19872014 ( $N=2073$ )

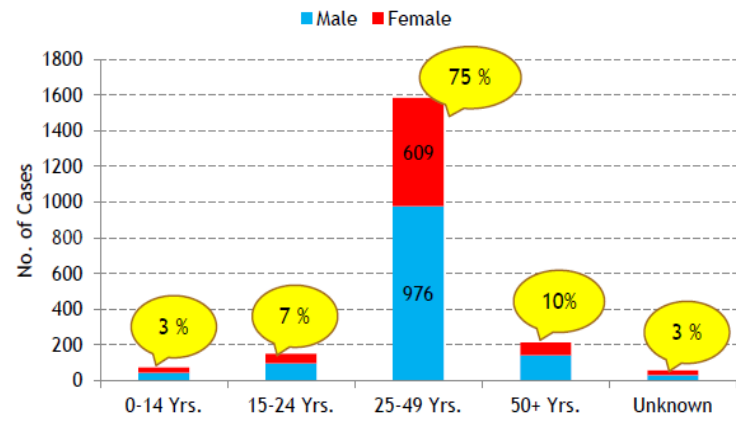

Seropositivity rate of different sub populations (Table 1) gives an overall picture of the HIV situation in the country. Testing different population groups in non-probability samples in various settings shows that seropositivity rate among blood donors were $0.01 \%$, private hospitals and laboratories rate was $0.03 \%$, antenatal mothers it was $0.003 \%$, STD clinic samples the rate was $0.16 \%$, among prisoner samples prevalence was $0.03 \%$ and TB clinic samples it was $0.24 \%$ while samples from armed forces had not shown positive cases.

Table 1: Seropositivity rate of different tested populations (non-probability samples)

\begin{tabular}{llll}
\hline $\begin{array}{l}\text { Type of sample } \\
\text { tested }\end{array}$ & $\begin{array}{l}\text { Number } \\
\text { positive }\end{array}$ & $\begin{array}{l}\text { Positivity } \\
\text { rate (\%) }\end{array}$ \\
\hline $\begin{array}{l}\text { Blood donor } \\
\text { screening }\end{array}$ & 380,367 & 25 & 0.01 \\
\hline $\begin{array}{l}\text { Private hospitals and } \\
\text { laboratories }\end{array}$ & 237,605 & 63 & 0.03 \\
\hline Antenatal mothers & 168,221 & 5 & 0.003 \\
\hline STD clinic samples* & 72,063 & 113 & 0.16 \\
\hline Tri forces & 20,191 & 0 & 0.00 \\
\hline $\begin{array}{l}\text { Prison HTC } \\
\text { programme }\end{array}$ & 13,803 & 4 & 0.03 \\
\hline TB clinic screening & 7,409 & 18 & 0.24 \\
\hline $\begin{array}{l}\text { Total } \\
\text { *STD clinic samples include; STD clinic attendees, testing } \\
\text { symptomatic patients and contacts }\end{array}$ & \\
\hline
\end{tabular}

In integrated biological and behavioural survey conducted in 2014/15, different subpopulations were tested using probability samples and the sero-prevalence among FSW was $0.81 \%$ and MSM was $0.88 \%$. However, FSWs and MSM prevalence in the districts of Colombo and Galle is $1 \%$ while injecting drug 
users' and Beach boys' HIV prevalence was $0 \%$ (Table 2).

Table 2: Integrated Biological and Behavioural Surveillance (IBBS) Survey among key Populations at Higher Risk of HIV in Sri Lanka

\begin{tabular}{lll}
\hline Population & Positive (\%) & $95 \% \mathrm{Cl}$ \\
\hline $\begin{array}{l}\text { Female sex workers (All) } \\
(N=1261)\end{array}$ & $0.81 \%$ & \\
\hline $\begin{array}{l}\text { Female sex workers } \\
\text { (Colombo and Galle) }\end{array}$ & $1.03 \%$ & $\begin{array}{l}0.3-1.7 \\
(95 \% \mathrm{Cl})\end{array}$ \\
\hline $\begin{array}{l}\text { Men who have sex with } \\
\text { Men (MSM) }(N=1217)\end{array}$ & $0.88 \%$ & \\
\hline$M S M($ Colombo and Galle) & $1.03 \%$ & $0.2-1.9$ \\
\hline$P W I D(N=326)$ & $0 \%$ & \\
\hline$B B(N=306)$ & $0 \%$ & \\
\hline
\end{tabular}

\section{HIV treatment cascade Sri Lanka}

HIV treatment cascade or HIV treatment continuum is another good way to understand the overall performance of prevention, treatment and care service delivery in the country. This cascade shows the outcome at different points in the continuum of HIV care (Fig 5). That is from estimates of PLHIVs to the final expected level of the control of the disease that is up to the adequate suppression of viral load. The $100 \%$ achievement of this is highly ambitious which cannot be practically achieved in chronic diseases such as HIV, DM etc. However, narrowing or closing of these gaps is important to control the transmission of HIV infection. The complete viral suppression among infected means the suppression of the HIV reservoir in the country. Then the treatment as prevention (TasP) becomes a reality. According to the HIV treatment cascade graph, only $48 \%$ are detected from the estimate, $23 \%$ are linked to care, $18 \%$ are put on ART and finally $8 \%$ will get the adequate VL suppression.
Figure 5: HIV treatment cascade; Sri Lanka 2014

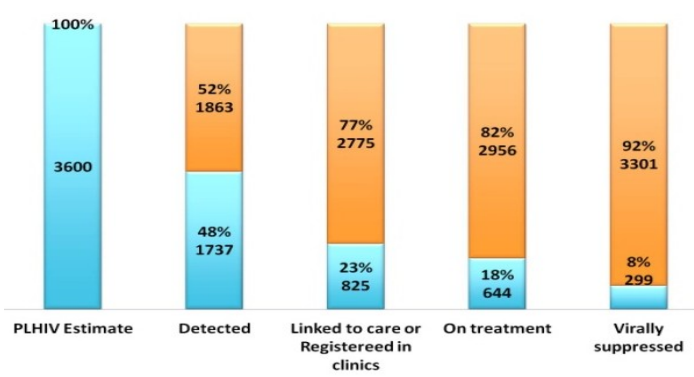

However, Condoms as a prevention (CasP) tool has been socialized among high risk groups to some acceptable level, according to the IBBS survey. Ninety-three percent (93\%) of female sex workers had used condoms with their last client. Condom use among MSM was $58 \%$ and in beach boys and people who inject drugs, it was $68 \%$ and $24 \%$ respectively. If we can reach $80 \%$ of a risk population and can make $60 \%$ of them to use condom consistently, the sexual transmission epidemic among that risk population can be reversed. According to the IBBS, condom use has reached to $60 \%$ or beyond but issue is that whether the coverage of these populations is enough. Respondent driven sampling (RDS) used in IBBS has its inherent volunteerism and biases especially when the number of waves are less in the RDS.

Table 3: Integrated Biological and Behavioural Surveillance (IBBS) Survey among key Populations at Higher Risk of HIV in Sri Lanka - Use of Condoms with last sexual partner

\begin{tabular}{lll}
\hline $\begin{array}{l}\text { Female sex workers (All) } \\
(N=1261)\end{array}$ & $93 \%$ & $\begin{array}{l}91.4-94.5 \\
(95 \% \mathrm{Cl})\end{array}$ \\
\hline $\begin{array}{l}\text { Men who have sex with Men } \\
(\mathrm{MSM})(\mathrm{N}=1217)\end{array}$ & $58 \%$ & $\begin{array}{l}54.1-61.8 \\
(95 \% \mathrm{Cl})\end{array}$ \\
\hline$B B(N=306)$ & $68 \%$ & $\begin{array}{l}61.8-73.3 \\
(95 \% \mathrm{Cl})\end{array}$ \\
\hline PWID $(N=326)$ & $24 \%$ & $\begin{array}{l}18.8-28.9 \\
(95 \% \mathrm{Cl})\end{array}$ \\
\hline
\end{tabular}

UNAIDS has given fast-track-targets named 90-90-90 as a target to be achieved by 2020. It is, detect $90 \%$, treat $90 \%$ and adequately suppress the virus among $90 \%$ on ART. We have another 5 years to reach this target. Next target is $95 \%-95 \%-95 \%$ by 2030 to end AIDS. 
This is a take home message to this audience; every stakeholder should contribute to narrow these gaps in the treatment cascade. Ministry of health or the National STD/AIDS Control Programme alone cannot do this because most of the gaps are due to social and structural barriers.

When we compare some of the developed countries, the final viral suppression in the cascade is achieved in different proportions by different countries. For example, in United States the final viral suppression is achieved only among $25 \%$ patients.

\section{Challenges in closing the gaps in HIV treatment cascade}

In the detailed HIV cascade, there are number of gaps at various points of the cascade. From estimate to case detection $52 \%$ gap exists. From case detection to clinic registration there is a $53 \%$ gap, while clinic registration to ART, the gap is $22 \%$. From ART to viral load testing the gap is $25 \%$ and from viral load testing to adequate suppression of viral load, the gap is $38 \%$.

I categorize these gaps in to pre-registration gaps (Fig 6) and post-registration gaps (Fig 7) for your easy reference. Pre-registration gaps denote the gaps from estimates to detection to clinic registrations. Each step has approximately about $50 \%$ gap. Postregistration gaps are from registration to ART to viral load testing to adequate viral suppression and the gaps in each step are about $25 \%$. Pre-registration gaps are huge compared to post-registration gaps.

\section{Figure 6: Pre-registration gaps}

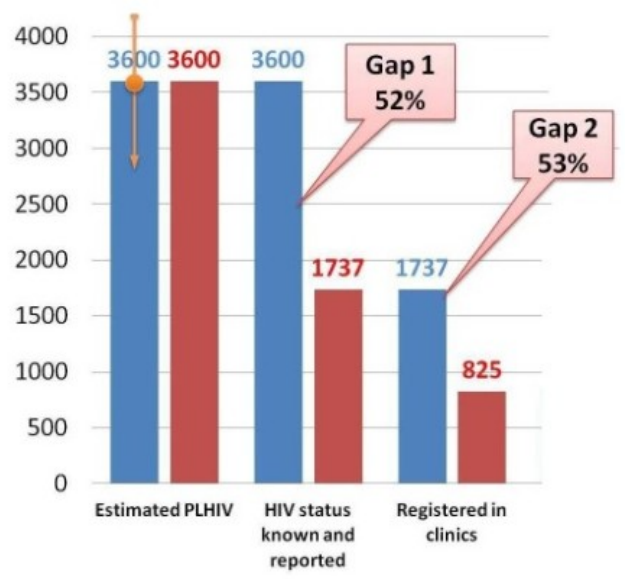

Highest attainable level of healthcare for HIV can only be achieved through taking necessary steps to "CLOSE THE GAP" or narrow the gaps.

The most important and difficult gaps exist at the pre-registration phase with average gap of approximately $50 \%$ at each step.

More robust data need to be fed for realistic estimation and projections including surveillance data, size estimation data, programmatic data. Methodological issues which occur in very low level epidemics need to be considered when calculating our estimates.

Widespread testing for case detection is a must and need to take necessary steps to mainstream HIV testing to all possible entry points in health or non-health sectors. Key populations coverage is a priority but should not be limited to them.

Creation of enabling environment by removing or mitigating barriers for access for testing and care through legal and policy reforms and strengthening right based approaches.

Creation of enabling environment at healthcare systems by reducing stigma and discrimination, ensuring confidentiality and making culturally competent workforce. 
Reasons for Post registration gaps (Fig 7) are multiple and they also need to be addressed holistically.

Figure 7: Post-registration gaps

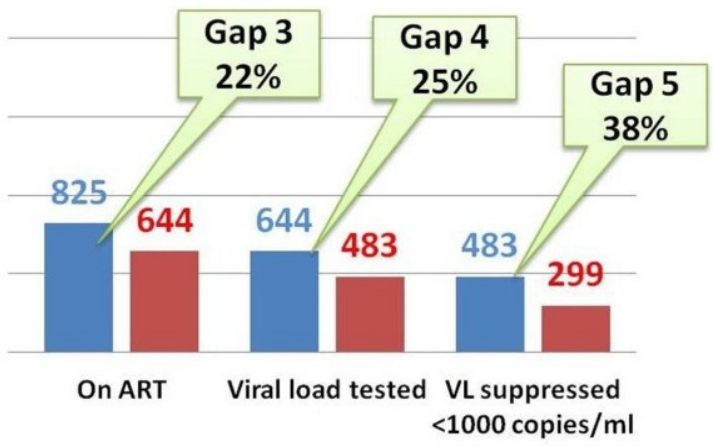

- Creation of enabling legal and policy environment by removing or mitigating barriers for access such as legal and policy barriers for treatment access, formulating laws for right to health and right to life

- Creation of enabling social environment by removing or mitigating social barriers such as stigma and discrimination, marginalization, homophobia, transphobia, lack of acceptance of sexual diversity, denial attitudes of the society for sex and sexuality

- Creating and enabling family environment for treatment access, such as family counselling and psychosocial support, financial assistance

- Creating an enabling self-mind to access for care by reducing effects of anxiety, non-concerned health behaviour, self-stigma, fatalism etc.

- Creation of enabling environment at healthcare systems with sensitive and culturally competent staff

- Law level of defaulter tracing and contact tracing due to some consent, confidentiality, financial and rights based issues and conflicts of human rights

- Lack of availability of VL testing at an accessible distance
- Adherence issues among patients

- Deviations for CAMs complementary and alternative medicines

- Change in guidelines for start of ART

HIV clinicians can play a major role in narrowing these post-registration gaps in the cascade.

\section{HIV in the broader concept of Sexual Health}

To reduce the pre and post registration gaps. It is important to address HIV in the broader concept of Sexual Health. Sexual Health is not merely the absence of disease, infirmity or dysfunction. It is the complete physical, emotional, mental and social wellbeing in relation to sexuality.

Sexuality includes biological sex, gender identities and roles, sexual attractions or sexual orientation, sexual preference, erotism, pleasure, intimacy, and reproduction. These dimensions are very diverse and complex and inter-relating. Promotion of sexual health is important than ever to address the gaps in HIV treatment cascade.

Therefore, I propose to transform STD clinics in to a different organizational structure. May be a "Sexual Health Centre" at district level as a multidisciplinary service delivery point where STD clinics, HIV clinics, LGBT clinics, Adolescent Sexual Health Clinics, Prevention department, and Sexual Health clinics can be accommodated with broader mandate for treatment, prevention advocacy for policy alternatives and enforcement for the interest of public health and right to health principles.

With the following remarks, I conclude my keynote address, at this important moment, I remember my late parents, $\mathrm{Mr}$ Lionel Karawita and Mrs Alice Karawita who were my strengths of life.

I got my school education from the Central College Anuradhapura and graduated from the faculty of medicine, University of 
Peradeniya and subsequent postgraduate studies at the University of Colombo.

I remember all my teachers including today's chief guest Prof. Ranjith Wijayawardena, my friends, relatives and everyone who associated with me in my life because I inspired most of the things from them.

Finally, I remember my wife, Muditha and my daughter Sarah and Son Channa who tolerated me and are beside me in my professional carrier.

Thank you everyone who have come today to grace this occasion.

Thank you very much!

\section{Acknowledgement}

- $\quad \operatorname{Dr}$ K. A. M. Ariyaratne, and the staff of the Strategic Information Management unit of the National STD/AIDS Control Programme for generating important information

- Dr Sisira Liyanage, Director, National STD/AIDS Control Programme

- Office bearers and the Council of the college of Venereologists

- Dr Sriyakanthi Beneragama for HIV and IBBS data 